\title{
Learning Style Preferences of Undergraduate Pharmacy Students in a Malaysian Public University
}

\author{
Edna Magdalena John1, Chin Fen Neoh ${ }^{1,2 \star}$, Long Chiau Ming ${ }^{1,3}$, Yet Hoi Hong ${ }^{4}$, Yahaya Hassan ${ }^{1}$ \\ ${ }^{1}$ Faculty of Pharmacy, Universiti Teknologi MARA, Puncak Alam Campus, Selangor, MALAYSIA. \\ ${ }^{2}$ Collaborative Drug Discovery Research (CDDR) Group, Pharmaceutical and Life Sciences Community of Research, Universiti \\ Teknologi MARA, Shah Alam Campus, Selangor, MALAYSIA. \\ ${ }^{3}$ Vector-borne Diseases Research Group (VERDI), Pharmaceutical and Life Sciences Community of Research, Universiti Teknologi \\ MARA, Shah Alam Campus, Selangor, MALAYSIA. \\ ${ }^{4}$ Department of Physiology, Faculty of Medicine, University of Malaya, Kuala Lumpur, MALAYSIA.
}

\begin{abstract}
Objectives: To compare the learning style preferences among pharmacy students at different stages of academic course and to determine the demographic variables that significantly influence the learning style preferences of these students. Methods: A 24-item self-report survey instrument, including the validated Pharmacists' Inventory of Learning Styles (PILS), was administered to all year 1 to year 4 pharmacy students at Universiti Teknologi MARA, Malaysia. Data (e.g. demographic variables, learning style preferences) collected were entered and analysed using SPSS version 21. Results: A total of 469 students completed the questionnaire; the majority were female $(385 / 469,82.1 \%)$ and year 4 pharmacy students $(156 / 469,33.3 \%)$. The dominant learning style preferred by the pharmacy students was assimilator $(n=189 / 469,40.3 \%)$, followed by converger ( $n=115 / 469,24.5 \%$ ). The learning style preference was similar across the 4-year pharmacy students with assimilator as the most preferred, followed by converger. There was no significant association between dominant learning style preferences and all the demographic variables $(p>0.05)$. A similar trend was observed in secondary learning style $(p>0.05)$. Conclusion: The majority of the pharmacy students belong to the category of assimilator type of learners. A variety of teaching methods should be implemented in pharmacy education to complement all learning styles and to provide a fair environment for all types of learners.
\end{abstract}

Key words: Assimilator, Converger, Learning styles, Pharmacy, PILS.

\section{INTRODUCTION}

Pharmacy education has a very important role in determining the quality of pharmacists who will work for the community in the future. It has the ability of transforming the profession towards a patient-centred one. ${ }^{1}$ In a move to ensure pharmacy professional competence and to meet the changing roles of pharmacists in the healthcare setting, pharmacy education around the globe has undergone substantial evolution in the recent years. ${ }^{1}$ However, the four-year undergraduate pharmacy course can be challenging for some students as the course is expected to cover all areas of pharmaceutical sciences. In addition, the wide coverage of topics and limited time in class could reduce the effectiveness of teaching-learning interaction. ${ }^{2}$ The lack of understanding on the learning style preferences of pharmacy students can lead to a mismatch of learning styles and teaching methods by instructors which can further cause stress and frustration to both parties. ${ }^{3}$ As a result, the learning process may be deemed an unproductive experience by both students and instructors.
Submission Date : 01-06-2016

Revision Date : :21-06-2016

Accepted Date : 22-06-2016

DOI: 10.5530/ijper.50.3.3

Correspondence:

Chin Fen Neoh,

Collaborative Drug Discovery

Research (CDDR) Group,

Pharmaceutical and Life

Sciences Community of

Research, Universiti

Teknologi MARA, Shah Alam

Campus, Selangor,

MALAYSIA.

Phone no: 603-32584708

E-mail: neohchinfen@

puncakalam.uitm.edu.my

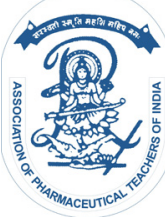

www.ijper.org 
Learning style is the "manner in which individuals choose to or are inclined to approach a learning situation". ${ }^{4}$ Different personalities will result in different learning styles. ${ }^{5}$ For instructors, knowing their students' learning style preferences will enable them to adapt their teaching methods to the learning styles of their students. ${ }^{3}$ Consequently, this can help to improve students' attitudes toward the courses and result in a better academic performance. ${ }^{6}$

To date, two studies have been conducted to determining the learning style preferences of undergraduate pharmacy students in Malaysia. ${ }^{27}$ However, none of these studies used the Pharmacists' Inventory of Learning Style (PILS) tool, which was specifically developed and validated for pharmacy education., ${ }^{8,9}$ PILS divided the learning styles of pharmacists into four groups: accommodator, assimilator, converger and diverger. ${ }^{8,9}$ The use of the well-validated tool in the pharmacy education setting would be more appropriate in measuring the learning style preferences as well as students' attitudes and feelings towards the courses they have taken. ${ }^{10}$ In addition, the learning style preferences of undergraduate pharmacy students in Universiti Teknologi MARA, Malaysia remain unknown. The identification of differences in learning styles among pharmacy students is important as this would promote an optimal teaching-learning process. In view of this, this study aimed to assess the learning style preferences of pharmacy students, to compare the learning style preferences among year 1, 2, 3 and 4 pharmacy students and to determine the demographic variables that might significantly influence the learning style preferences of pharmacy students.

\section{MATERIAL AND METHODS}

\section{Study design, participants and settings}

A cross-sectional study was conducted between March and June 2015 at the Faculty of Pharmacy, Universiti Teknologi MARA, Malaysia. Ethics approval from Universiti Teknologi MARA Research Ethics Committee was obtained prior to the commencement of this study [600-RMI (5/1/6)]. All undergraduate pharmacy students, from year 1 to 4 , were invited to participate in the study. The minimum sample size required was 253 pharmacy students; calculated using Raosoft ${ }^{\circledR}$ (Sample Size Calculator; Raosoft inc.) ${ }^{11}$ with a confidence interval of $95 \%$ and a margin of error of $5 \%$. The surveys were distributed in a lecture hall before the lecture started. A short briefing was given to provide clarification on the survey. Students were given ample time to answer the survey and the surveys were collected on the same day. Completion of the survey implied consent.

\section{Study Instrument}

A 24-item self-report survey instrument which consists of two sections was administered. Section 1 consists of socio-demographic items including age, gender, year of study, highest achieved qualification, as well as the state and location of institutions for their highest achieved qualification. Section 2 consists of the validated PILS. ${ }^{8,9}$ This inventory is designed to identify the dominant learning style and the secondary learning style of respondents. There are 17 questions in this inventory with four options for response namely, usually, sometimes, rarely and bardly. The inventory measures two axes of learning. The first axis focuses on structured versus unstructured while the second concentrates on doer versus reflector. The inventory categorised learning styles into four groups namely accommodator, assimilator, converger and diverger. 8,9

\section{Statistical Analysis}

Data collected were analysed using Statistical Package for Social Sciences (SPSS) Program version 21 (IBM SPSS Statistics for Windows, Armonk, NY: IBM Corp.). Descriptive analysis was employed to describe demographic data of the respondents. The associations between categorical variables (e.g. demographic variables) and learning style preference were examined using Chi-square tests of independence; the significance level was set a priori at $\mathrm{p}<0.05$.

\section{RESULTS}

Of the 742 undergraduate pharmacy students surveyed, $469(63.2 \%)$ completed the questionnaire. The demographic data of the participants are summarised in Table 1 . The majority of the participants were female $(82.1 \%)$ and Malay (96.6\%). The mean age was $21.4 \pm$ 1.3 years old. The highest number of participants were from year $4(\mathrm{n}=156 / 469,33.3 \%)$, followed by year 2 $(\mathrm{n}=154 / 469,32.8 \%)$, year $3(\mathrm{n}=97 / 469,20.7 \%)$ and year $1(\mathrm{n}=62 / 469,13.2 \%)$. There was an almost equal distribution of the highest education achieved prior to entering pharmacy school, namely foundation (35\%), matriculation (33\%) and diploma (29.6\%). Slightly more than half of the students $(51.2 \%)$ claimed that their previous institution was in a suburban area.

In all, the dominant learning style (Figure 1) preferred by the students was assimilator ( $\mathrm{n}=189 / 469,40.3 \%$ ), followed by converger $(\mathrm{n}=115 / 469,24.5 \%)$, diverger $(n=66 / 469,14.1 \%)$ and accommodator $(n=15 / 469,3.2 \%)$. About $18 \%(\mathrm{n}=84 / 469)$ of the pharmacy students had preferences for two or more learning styles and in this study, we referred this as multimodal. The secondary learning style (Figure 2) preferred by students 


\begin{tabular}{|l|c|}
\hline \multicolumn{2}{|c|}{ Table 1: Characteristics of pharmacy students } \\
(n=469)
\end{tabular}

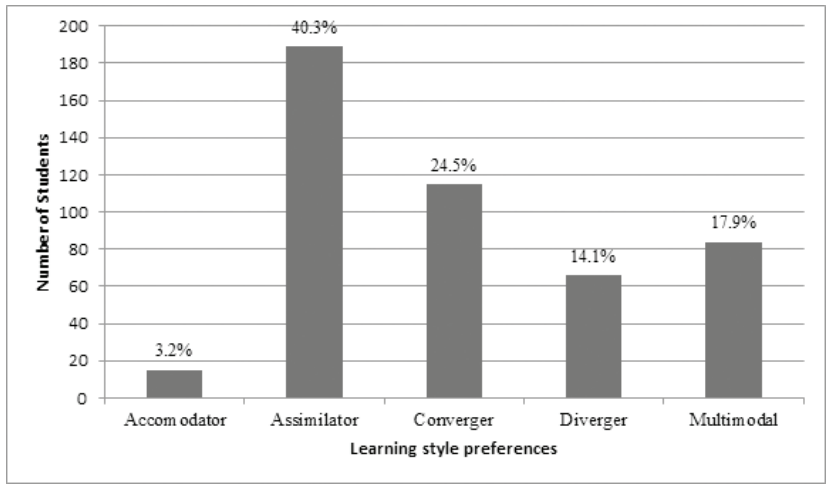

Figure 1: The dominant learning style of pharmacy students $(n=469)$.

was mainly converger ( $\mathrm{n}=119 / 46925.4 \%$ ), followed by multimodal ( $\mathrm{n}=111 / 469,23.7 \%)$, diverger $(\mathrm{n}=90 / 496$, $19.2 \%)$, assimilator $(\mathrm{n}=87 / 469,18.6 \%)$ and accommodator $(\mathrm{n}=62 / 469,13.2 \%)$.

There were no differences between pharmacy students from year 1 to year 4 in their preference for primary learning style of which assimilator was the most common learning style of choice [year $1(\mathrm{n}=23 / 62,37.1 \%)$, year $2(\mathrm{n}=64 / 154,41.6 \%)$, year $3(\mathrm{n}=33 / 97,34.0 \%)$, year $4(\mathrm{n}=69 / 156,44.2 \%)]$. Converger was the most common secondary learning style in year $1(\mathrm{n}=14 / 62$, $22.6 \%)$ and year $2(n=43 / 154,27.9 \%)$ while multimodal was the most common secondary learning style in year $3(\mathrm{n}=26 / 97,26.8 \%)$ and year 4 $(\mathrm{n}=39 / 156,25.0 \%)$. In all years of study, accommodator was the most unpopular learning style. There were no

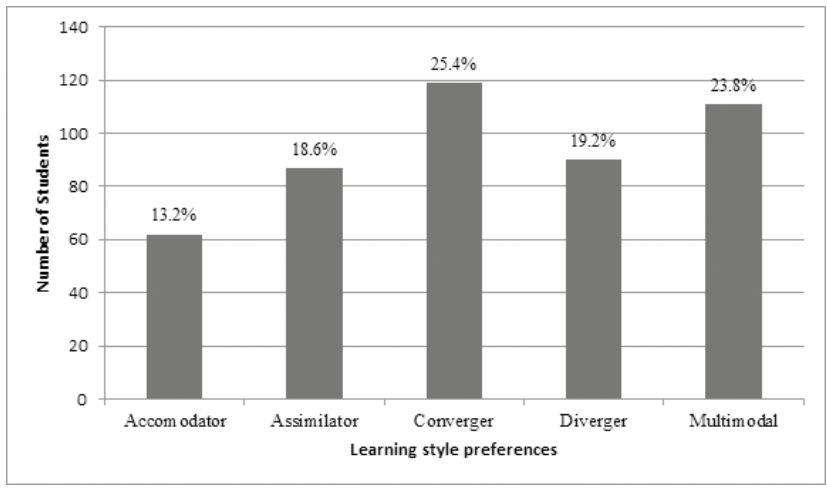

Figure 2: The secondary learning styles of pharmacy students $(n=469)$.

associations between dominant learning style preferences and gender $(p=0.62)$, year of study $(p=0.84)$, ethnicity ( $p=0.16)$, level of education $(p=0.96)$, state of origin $(\mathrm{p}=0.99)$ and location of previous higher institution $(p=0.26)$. Similar trends were observed in secondary learning style.

\section{DISCUSSION}

The understanding of students' learning styles can help instructors to employ appropriate teaching methods which are effective in delivering the course content as well as capable of making the learning process an interesting experience as well. In addition, students who know their learning styles will be able to practise suitable learning methods in their studies regimen to enhance and maximise their individual learning capability. One of the strengths of this study, as compared to other studies conducted in Malaysian pharmacy schools, 2,7 is the use of PILS as the tool in assessing pharmacy students' learning style preferences. The choice of study instrument is important to ensure that the assessment is relevant and valid in the study setting, and thus, comparisons with other studies conducted using the same tool can be made. ${ }^{4}$ PILS was developed and validated by Zubin Austin in 2004 with the collaboration of 40 pharmacists; it is the first specific inventory validated for pharmacy practice and education use with a high degree of reliability (Cronbach's alpha value of 0.85-0.90). ${ }^{8,9}$ This inventory was developed based on Kolb's Learning Style Inventory and is designed to identify both dominant and secondary learning styles. Moreover, PILS provides a unique pharmacist-specific model for defining, describing, and measuring learning styles.

In this study, the dominant learning styles of the pharmacy students was assimilator (40.3\%) while the secondary learning style was converger (25.4\%), consistent with previous studies by Crawford et al. ${ }^{12}$ and Robles et al. ${ }^{13}$ 
Assimilator learners love to work on their own at their own timing and prefer to study in an organised learning environment; they always strive to do their best because grades are important to them. ${ }^{14}$ In the real learning environment, assimilators prefer to do individual assignments and like to receive feedback regarding their performance. ${ }^{12}$ Assimilator learning styles have been associated with jobs which value conceptual models rather than the practical such as jobs in the fields of biology, education, teacher, law, sociology, librarianship and mathematics. ${ }^{15}$ On the other hand, convergers are referred to as practical learners. They prefer to work fast and want to complete a task as soon as possible without minding the way of completing the task. Convergers, therefore, tend to become leaders and enjoy the attention. ${ }^{12}$ They prefer to work in small groups and are very competitive in terms of performance. ${ }^{12}$ Converger learners have been associated with jobs requiring problem solving, analysing, planning and decision making such as in the fields of medicine, engineering, economics as well as computer science. ${ }^{15}$ Consistent with the abovementioned literatures, ${ }^{12,13,15}$ the preferred learning styles (i.e. assimilator, converger) reported by the pharmacy students in this study was suitable to their field of study.

In this study, no significant differences were found in learning style preferences among year 1 to year 4 pharmacy students; assimilator was the primary learning style preferred by most students while converger as the secondary learning style. This finding is consistent with the studies by Crawford et al. ${ }^{12}$ and Robles et al..$^{13}$ that stated there were no significant differences in learning styles between the third and fourth year of pharmacy students in the US setting. However, unlike the findings from the previous studies, there were no significant associations between learning style preferences and the demographic data indicated in this study. Crawford et al. ${ }^{12}$ reported a significant association between gender and PILS learning styles. The difference could be due to the unequal numbers of male and female participants in the current study. The number of female students overwhelmed the number of male students by more than 100\% and thus any significant association between gender and learning style could not be identified. Likewise, ethnicity had no influence on the learning styles of the pharmacy students which supported the two studies conducted in the US setting. ${ }^{12,13}$ However, this finding contradicted the Malaysian study conducted by Aziz et al. ${ }^{2}$ which indicated that Chinese and Malay pharmacy students significantly preferred the reflector learning style as compared to Indian students. The ethnicity influence was not seen in the current study because Malays comprised more than $95 \%$ of the participants.
Pharmacy students from the same region may share similar learning styles due to similarities in culture and environment. This current study complemented a previous study which identified learning styles among pharmacy students in the University of Malaya (UM). ${ }^{2}$ In the UM study, it was reported that the majority of the students were reflectors. ${ }^{2}$ The reflector learning process involves observing, listening, thinking before taking action and also being thorough ${ }^{16}$ while assimilators are described as passive and reflective learners who prefer lectures that focus on concepts, assigned tasks, readings and examinations. ${ }^{17}$ This statement clearly indicates that there are connections between the reflector and assimilator learning styles in which both types of learners concentrate on their inner self. Thus, it would appear that Malaysian pharmacy students share similar learning styles.

Each learning style represents a different way of learning and each has its own strengths and weaknesses. ${ }^{4}$ It would be beneficial to include all four stages of the learning model consisting of the two dimensions given by Kolb's Theory, namely, the dimensions of grasping experience which include concrete experience and abstract conceptualisation, and the dimension of transforming experiences that include reflective observation and active experimentation. ${ }^{14}$ In this way, we can challenge students to learn things out of their comfort zones while enhancing their preferred way of learning in order for them to become versatile learners. ${ }^{18}$ Moreover, they can develop their interpersonal skills as future pharmacists by adopting different learning styles. ${ }^{12}$ As the pharmacy profession is moving forward towards more patient-centred care, ${ }^{19}$ it is important for students to improve their social skills and interpersonal skills as a preparation for their future profession as pharmacists.

Assimilator and converger learners should be exposed to and taught social and interpersonal skills as they are more interested in ideas and concepts rather than in people or social issues. ${ }^{18}$ In addition, a recent study stated that assimilators seem to have conflict over social learning ${ }^{20}$ and are dependent on the instructor for learning material and direction. ${ }^{17}$ In order to overcome this situation, Janing ${ }^{17}$ proposed that they should be exposed to different learning activities that require them to seek knowledge on their own, look for solutions to problems and make decisions on their own. As learning styles are neither static nor determined by personality traits alone $^{12}$ but can change from time to time as a result of maturity, professional socialization and institutional culture, ${ }^{3,13}$ it is possible for students to adopt different learning styles to improve their learning process and eventually, to improve themselves. 
Traditionally, pharmacy education focuses first on facts and pieces of information ${ }^{5}$ which is a traditional form of teaching and would only be beneficial to a certain group of students. Nevertheless, traditional teaching methods such as lectures are still relevant and proven to still be the primary teaching method of choice among the students. ${ }^{20,21}$ As pharmacy profession is evolving rapidly, it is relevant for active learning to be embraced in pharmacy education. Active learning such as Problem Based Learning (PBL), case study and inquiry-based learning can expose students to a more realistic application of their education. ${ }^{22}$ Therefore, active learning methods should be applied together with traditional methods in pharmacy education in order to enhance the learning process of pharmacy students. Our study, however, has several limitations. Since we relied on selfreporting method, it may not reflect the actual learning style preference of the pharmacy students. The modest response rate in the current study could be another limitation as non-respondents may have different learning style preferences. Data obtained from a single university may not be able to generalisable to other universities in Malaysia.

\section{CONCLUSION}

The dominant learning style preferred by the pharmacy students in this study was assimilator followed by converger as the secondary learning style. There was no difference in the learning styles preferences among pharmacy students from years 1,2,3, and 4. The preferences for learning style were independent of the demographic data. Although assimilator and converger were the predominant learning styles, the other learning styles should not be neglected when revising the pharmacy curricula as the teaching methods should benefit all students. That is why a variety of teaching methods should be implemented in pharmacy education to cater to all learning styles and provide a fair environment for all types of learners. Since learning is an ever-changing process, it would be possible to challenge students to learn through different methods than the methods they are already comfortable with and at the same time enhance their preferred way of learning things.

\section{ACKNOWLEDGEMENTS}

We thank the UiTM pharmacy students for their participations in this study.

\section{CONFLICT OF INTEREST}

The authors declare that there is no conflict of interest.

\section{ABBREVIATION USED}

PILS: Pharmacists' Inventory of Learning Styles ; SPSS: Statistical Package for Social Sciences ;UM: University of Malaya ; PBL: Problem Based Learning.

\section{REFERENCES}

1. Hassali MA, Li V, See OG. Pharmacy practice in Malaysia. J Pharm Pract Res. 2014;44(3):125-8. http://dx.doi.org/10.1002/jppr.1024.

2. Aziz Z, Yi TX, Alwi S, Jet CN. Learning Style Preferences of Pharmacy Students. Eur J Soc Behavior Sci. 2013;4(1):819-35. http://dx.doi. org/10.15405/FutureAcademy/ejsbs(2301-2218).2012.4.14 .

3. Teevan CJ, Li M, Schlesselman LS. Index of learning styles in a US school of pharmacy. Pharm Prac. 2011;9(2):82-7. PMCid:PMC3969830.

4. Cassidy S. Learning styles: An overview of theories, models, and measures. Educ Psychol. 2004;24(4):419-44. http://dx.doi.org/10.1080/0144341042000 228834.

5. Shuck AA, Phillips CR. Assessing pharmacy students' learning styles and personality types: a ten-year analysis. Am J Pharm Educ. 1999;63(1):27-33.

6. Romanelli F, Bird E, Ryan M. Learning styles: a review of theory, application, and best practices. Am J Pharm Educ. 2009;73(1):9. http://dx.doi. org/10.5688/aj730109; PMid:19513146.

7. Elkalmi RM, Alshami AKM, Ahmad A, Umair M, Khan NSAR, Alkoudmani RM. Assessment of learning style preferences of pharmacy students: Findings from public university of Malaysia. Indian J Pharm Educ Res. 2015;49(4):26671. http://dx.doi.org/10.5530/ijper.49.4.4.

8. Austin Z. Learning styles of pharmacists: impact on career decisions, practice patterns and teaching method preferences. Pharm Educ. 2004;4(1):13-22. http://dx.doi.org/10.1080/1560221042000193310.

9. Austin Z. Development and validation of the pharmacists' inventory of learning styles (PILS). Am J Pharm Educ. 2004;68(2):37.

10. Novak S, Shah S, Wilson JP, Lawson KA, Salzman RD. Pharmacy students' learning styles before and after a problem-based learning experience. Am J Pharm Educ. 2006;70(4):74. http://dx.doi.org/10.5688/aj700474; PMid:17136193:PMCid:PMC1636984.

11. Raosoft I. Sample Size Calculator. Available at: http://www.raosoft.com/ samplesize.html.

12. Crawford SY, Alhreish SK, Popovich NG. Comparison of learning styles of pharmacy students and faculty members. Am J Pharm Educ. 2012;76(10):192. http://dx.doi.org/10.5688/ajpe7610192; PMid:23275657 PMCid:PMC3530054

13. Robles J, Cox CD, Seifert CF. The impact of preceptor and student learning styles on experiential performance measures. Am J Pharm Educ. 2012;76(7):128. http://dx.doi.org/10.5688/ajpe767128; PMid:23049100 PMCid:PMC3448466.

14. Kolb DA. Experimental Learning. Englewood Cliffs, NJ: Prentice-Hall. 1984.

15. Bhat MA. The effect of learning styles on problem solving ability among high school students. Int J Advances Soc Sci and Human. 2014;2(7):1-6.

16. Honey P, Mumford A. The Manual of Learning Styles (3rd ed.) Maidenhead: Peter Honey. 1992.

17. Janing J. Linking teaching approaches and learning styles: how can it help students? Emergency Med Serv. 2001;30(9):77-80. PMid:11563349

18. McCarthy M. Experiential learning theory: From theory to practice. J Busi Econ Res. 2010;8(5):131-40. http://dx.doi.org/10.19030/jber.v8i5.725.

19. Cipolle RJ, Strand LM, Morley PC. Pharmaceutical care practice: the patientcentered approach to medication management. McGraw-Hill Medical. 2012.

20. Lawrence WK. The experience of contrasting learning styles, learning preferences, and personality types in the community college English classroom. 2014

21. Choi FD, Yu AMM, Loquias MM. Learning syles of pharmacy students in the University of the Philippines-Manila (UP Manila). Int J Pharm Tech Pract. 2014;5(2):949-55.

22. Stewart DW, Brown SD, Clavier CW, Wyatt J. Active-learning processes used in US pharmacy education. Am J Pharm Educ. 2011;75(4):68. http://dx.doi. org/10.5688/ajpe75468; PMid:21769144. 